\title{
A Study on Acceptance Factors of Compensation App
}

\author{
Dong-Jin Choi and Yong-Tae Shin \\ $L G U+$, South Korea \\ School of Computer Science and Engineering, Soongsil Univ. South Korea \\ super301c@naver.com,shin@ssu.ac.kr
}

\begin{abstract}
Compensation apps, called money-making apps, are more effective than traditional ads because they are more immersive and less disliking. The success of the reward service is to attract a large number of subscribers and install or run an advertising application to make the company's advertising a major source of revenue. As mobile phones become more popular, many games are being released, and reward apps that offer rewards for a certain amount of advertising are being launched with various services. As the leisure time increases due to economical liberalization, shortening working hours, and spreading the five-day workweek, compensation apps that pay a certain amount of money are the factors that lead to user's time. In particular, from the point of view of students who are currently unemployed, they do not cause intoxication or economic devastation in nature, so their severity is considered negligible and is often used. On the positive side, we can not deny that all members of society are in financial difficulties and that some money is being collected. There is not much research on reward app, so this study will contribute to search for reward service activation strategy. Especially, it is difficult to verify the independent variables influencing the use effect. Therefore, we study the factors affecting the acceptance intention by presenting the integrated model using the protection motive theory and the planning action theory to verify the effect of the compensation advertisement.
\end{abstract}

Keywords: Compensation App, Protection Motivation Theory, Technology Acceptance Model, Planning Behavior Theory, Compensation, Acceptance Intention

\section{Introduction}

The purpose of this study is to identify the factors affecting purchase motivation, acceptance intention, recommendation intention, and purchase intention associated with gambling on many reward - based app services. It is characterized by its high level of immersion and low antipathy toward the above mentioned method, and it is easier to deliver than existing advertisements. According to KISA (KISA, 2013), mobile ads are classified into 6 types by adding compensation ads to mobile app DP ads, In_App ads, text ads, video ads, and search ads. New words such as Schumer are appearing. The reimbursement service knows that the subscriber attraction is KSF. The promotion of rewarding apparel can be developed through the application of the law, individual attitude, and equity. In conclusion, whether or not it is gambling to depend on the attitude to the person using the app. Due to the widespread use of mobile devices, many games are being released. Among them, rewarding apps that compensate a certain amount of advertisements tends to be released in a variety of services. As the leisure time is increased due to the economical and leisure time of the people, the working time is shortened, and the 5 - day workweek spreads weekly, I have found the means to consume such time. Moreover, the reward app giving the schedule reward is the factor of pulling

Received (October 7, 2017), Review Result (January 10, 2018), Accepted (February 2, 2018) 
the user 's wisdom. Especially, it is difficult to find a job nowadays. In its nature, it does not cause addiction or economic devastation, so it has some gait characteristics, but its severity is considered to be insignificant. The positive side cannot be denied in terms of being provided with the money that is collected nowadays, where all members of the society are experiencing economic difficulties. Research on compensation advertising is very limited, and so far research has not contributed much to finding strategies to activate compensation service. In particular, there is a difficulty in verifying the independent variables influencing the acceptance factors. Therefore, we want to increase the explanatory power of the dependent variable by applying the protection motivation theory and the planning action theory to verify the effect of the compensation app.

\section{Related Research}

Since reward apps are a type of smart ad, the motivation for using smart ads is the starting point. According to a preliminary study by Choi Min Wook (2015), Lee Jung Ki (2015), Kim Yong Dong and Kim Hwa Dong (2014), Yoo Seung Yeop and Kim Jin Hee (2014), there were six types of curiosity, convenience, leisure time, information acquisition, respectively. These various usage motives can be identified as independent variables of effect prediction and can be helpful in explaining the dependent variables by reconfirming the usage motives. In terms of the use effect, the attitude (Park Jong seok, Choi Yong Seok, Kwon Hyuk In, 2014), the recommendation intention (Han Mal Yum, Yang Young, Sung Youl Hong, 2015; Yoo Seung Yeop, Kim Jin Hee, 2014), Continued use behavior, intent to purchase advertised product or service (Kim Tae Woo, Han Mi Jeong, 2015) and acceptance intention (Lee Jung Gi, Kang Kyoung Soo, 2015).

\subsection{Gambling}

The hoisting person is called the 'play person' and the play is included in all cultural elements. Humanity has created and developed culture through play. Thus, human beings may be born to play. It can be difficult to control what falls into play than work. Play does not seek indirect and practical purposes, and the only motive of movement is the mental or physical activity in the joy of play itself. Play is an activity that proceeds according to certain rules and rules recognized by all participants, namely play rules, where there are accomplishments, failures, winnings, and losses. Roger Cayyu also distinguishes the characteristics of play by competition, fortune, mock, and dizziness, and distinguishes play that depends on fortune. Define play as free activity, isolated activity, undetermined activity, unproductive activity, ruleless activity, and fictitious activity. More research is needed on the extent to which reward apps encourage gambling because it is difficult to answer positively because empirical research and research have not been done yet. Depending on the attitude to the person using the app (frequency of use or access time), you can see the degree of gambling and addiction. The use of apps with a certain distance from immersion do not create a problem of addiction. When a person cannot set a boundary, he can think that he will become addicted. In other words, it becomes addicted because it is so intense. However, it can be problematic to prevent unilaterally doing so by suppressing human free will.

\subsection{Service Classification}

DMC media, NAS Media, KT Economic Research Institute, Kim Tae Woo, and Yeom Dong Seop define compensation services as follows. DMC media was divided into the following categories: ad-viewing type $(74.1 \%)$, app install type $(57.8 \%)$, quiz type (29.2\%), social media opinion type (15.9\%), subscription type (11.7\%) and survey type NAS media were classified as first generation and second generation. The research institute of KT economic management classifies it into the always-exposed type (lock 
screen-advertisement, telephone receiving-advertisement) and participation / action type (reward according to mission - It is classified into eight categories: audience type, counseling type, app install type, app execution type, event participation type, unlock type, quiz type, and membership type. In the study on the influence of the smartphone reward app type of the recommendation intention, Yeom Dong Seop proposed a classification similar to the existing ones (advertisement type - advertisement viewing type, unlocked type, phone type, mission type - And other types of social content, lifestyle, entertainment, shopping, and social media. It is also possible to divide into two categories: social media, executive type, social media opinion expression, subscription type, survey type, event participation type and quiz.

\subsection{Service Features}

There are more than 300 reward services currently in service, such as Cash Slide, Nexon Play, Latte Screen, Honey Screen, Mobile Company, MoneyYo, Doit Survey, Who-Cache, and InfoCoin. Regardless of type, advertisers have the advantage of being a win-win strategy for advertisers who advertise their own products and users who make money by just watching advertisements, and there are many users for advertisers. As of late 2012, DMC media survey shows that $76.9 \%$ of smartphone users are aware, and $37.7 \%$ have used it for the past year. Meanwhile, CJ E \& M, NHN, KakaoTalk and other large companies have become more popular. If you are just looking at the ads for the user, it's money. In fact, if you use two rewards apps every 30 minutes, you will earn about 5,000 won a month. On the other hand, the disadvantage is that in terms of future market expansion, many new services launch accelerates competition, and at the same time, there are cases of damages that do not make any compensation. I am used to the use of the side, and can be annoying enough to pay the price just by looking at the advertising. At first, I tried to actively use the magic, but this does not accumulate as much money as the business without any action suddenly stop the service and compensation. There is a case of unreliability, and a distrust is generated. In order to be covered by the e-commerce law, telecom vendors should advertise and sell goods to consumers. Compensation apps do not apply to them, so they are legally blind and even if they are actively used, they are tired of overlapping ads. do. Most of the domestic reward apps receive advertisements through CPI agencies such as TNK Factory, IGA Works, and NeXT Apps, so I installed the game app in the reward app A and received the points. The reward app B is duplicated in the same game ad. The user is annoyed and the advertiser has a room for wasting advertising expenses. For advertisers, the most fatal disadvantage of reward apps is user retention. If you advertise through the reward app, the cherry picker who is trying to reward you will lose the advertising efficiency in the long term because it is about $90 \%$ of the time that the app is deleted after installation. Service providers' deficits are increasing due to the slow increase of large advertisers. Reward apps typically take a large number of CPI (Cost Per Install) types instead of the traditional CPC (Cost Per Click) method, reducing the resistance of advertisements and compensating for affiliate offer benefits. Typically, Adlatte is advertising with many advertisers with the slogan "You can drink a latte in 10 minutes a day" and it is downloading 22,000 downloads a day. It's clear that the contrast is clear, but there are still a lot of users using reward apps, and it's clear that there are new competing apps coming into the market, but whatever direction you evolve in the future, we expect to grow in direction. Mobile reward app for improving usability In the symbol analysis of GUI content, effective communication methods include the indicator type, the icon type, the symbol type, the indicator type is the metaphor such as coin, banknote, piggy bank and the icon type is the app clover, Cache, and so on. The mobile ad market, including reward apps, grew 31.3\% from 1.374 trillion won in 2015 to 1.82 trillion won in 2016. Advertisement can be categorized into four categories: message, search, display, and reward. Double compensation advertisement is an advertisement type that provides points to users when users perform various types of rewards, and $37.5 \%$ of the 
respondents perceived it, and $25.5 \%$ of the respondents. As a result, $62.5 \%$ of the respondents took action such as searching, purchasing, visiting the homepage, and recommending acquaintances. There are more than 300 reward services currently in service, such as Cash Slide, Nexon Play, Latte Screen, Honey Screen, Mobile Company, MoneyYo, Doit Survey, Who-Cache, InfoCoin. Regardless of type, advertisers have the advantage of being a win-win strategy for advertisers who advertise their own products and users who make money by just watching advertisements, and there are many users for advertisers. As of late 2012, DMC media survey shows that $76.9 \%$ of smartphone users are aware, and $37.7 \%$ have used it for the past year. Meanwhile, CJ E\& M, NHN, KakaoTalk and other large companies have become more popular. If you are just looking at the ads for the user, it's money. In fact, if you use two rewards apps every 30 minute, you will earn about 5,000 won a month. On the other hand, the disadvantage is that in terms of future market expansion, many new services launches accelerates competition, and at the same time, there are cases of damages that do not make any compensation. I am used to the use of the side, and can be annoying enough to pay the price just by looking at the advertising at first I tried to actively use the magic, but this does not accumulate as much money as the business without any action suddenly stop the service and compensation There is a case of unreliability, and a distrust is generated. In order to be covered by the e-commerce law, telecom vendors should advertise and sell goods to consumers. Compensation apps do not apply to them, so they are legally blind and even if they are actively used, they are tired of overlapping ads. do. Most of the domestic reward apps receive advertisements through CPI agencies such as TNK Factory, IGA Works, and NeXT Apps, so I installed the game app in the reward app A and received the points. The reward app B is duplicated in the same game ad. The user is annoyed and the advertiser has a room for wasting advertising expenses. For advertisers, the most fatal disadvantage of reward apps is user retention. If you advertise through the reward app, the cherry picker who is trying to reward you will lose the advertising efficiency in the long term because it is about $90 \%$ of the time that the app is deleted after installation. Service providers' deficits are increasing due to the slow increase of large advertisers. Reward apps typically take a large number of CPIs (Cost Per Install) types instead of the traditional CPC (Cost Per Click) method, reducing the resistance of advertisements and compensating for affiliate offer benefits. Typically, Adlatte is advertising with many advertisers with the slogan "You can drink a latte in 10 minutes a day" and it is downloading 22,000 downloads a day. It's clear that the contrast is clear, but there are still a lot of users using reward apps, and it's clear that there are new competing apps coming onto the market, but whatever direction you evolve in the future, we expect to grow in direction. Mobile reward app for improving usability in the symbol analysis of GUI content, effective communication methods includes the indicator type, the icon type, the symbol type, the indicator type is the metaphor such as coin, banknote, piggy bank and the icon type is the app clover. Cache, and so on. The mobile ad market, including reward apps, grew $31.3 \%$ from 1.374 trillion won in 2015 to 1.82 trillion won in 2016. Advertisement can be categorized into four categories: message, search, display, and reward. Double compensation advertisement is an advertisement type that provides points of users when users perform various types of rewards, and $37.5 \%$ of the respondents perceived it, and $25.5 \%$ of the respondents. As a result, $62.5 \%$ of the respondents took action such as searching, purchasing, visiting the homepage, and recommending acquaintances. 
Table 1. Comparison of Mobile and Online Ads

\begin{tabular}{|c|c|c|c|c|}
\hline \multicolumn{2}{|c|}{ Ad. format } & Format & Pros & Cons \\
\hline \multirow{7}{*}{$\begin{array}{c}\text { Mobile } \\
\text { advertising }\end{array}$} & Message & SMS, MMS & Cheap packet rates & $\begin{array}{l}\text { No variety of } \\
\text { expressions }\end{array}$ \\
\hline & Search & Text and Ad impressions & $\begin{array}{l}\text { Exploration step } \\
\text { exposure possible }\end{array}$ & $\begin{array}{l}\text { Search quality is } \\
\text { poor }\end{array}$ \\
\hline & Banner & Image, rolling image & $\begin{array}{l}\text { Exposure to various } \\
\text { formats and locations }\end{array}$ & Low attention \\
\hline & Application & $\begin{array}{l}\text { Inserting ads in an ad } \\
\text { application and an } \\
\text { application }\end{array}$ & $\begin{array}{l}\text { User selected, } \\
\text { Aggressive } \\
\text { advertising } \\
\text { engagement }\end{array}$ & Limited target \\
\hline & Video & Flash Video & High attention & $\begin{array}{c}\text { Low-quality low- } \\
\text { quality }\end{array}$ \\
\hline & SNS & Facebook, Twitter & communication & $\begin{array}{c}\text { Information leakage } \\
\text { risk }\end{array}$ \\
\hline & QR code & QR code distribution & $\begin{array}{l}\text { Applied to various } \\
\text { locations }\end{array}$ & Limited Action \\
\hline \multirow{5}{*}{$\begin{array}{c}\text { Online } \\
\text { advertising }\end{array}$} & Banner & Flash, Animation & $\begin{array}{c}\text { Can be produced } \\
\text { easily and in various } \\
\text { ways }\end{array}$ & Low attention \\
\hline & Pop-up & $\begin{array}{l}\text { Pop-up impressions on your } \\
\text { browser }\end{array}$ & Compulsory exposure & $\begin{array}{l}\text { Interference with } \\
\text { web surfing }\end{array}$ \\
\hline & Contents AD & Insert In-Content Ads & $\begin{array}{l}\text { Make natural ad } \\
\text { impressions }\end{array}$ & $\begin{array}{l}\text { Interference with } \\
\text { content use }\end{array}$ \\
\hline & Rich-media & Video Streaming & High attention & $\begin{array}{l}\text { Interference with } \\
\text { web surfing }\end{array}$ \\
\hline & $\begin{array}{l}\text { Keyword } \\
\text { search AD }\end{array}$ & Text and Ad impressions & $\begin{array}{l}\text { Exploration step } \\
\text { exposure possible }\end{array}$ & $\begin{array}{l}\text { Search quality is } \\
\text { poor }\end{array}$ \\
\hline
\end{tabular}

\section{Research Methods and Hypotheses}

A study model of the integrated model of the motivation theory and the plan behavior theory is shown in Figure 1.

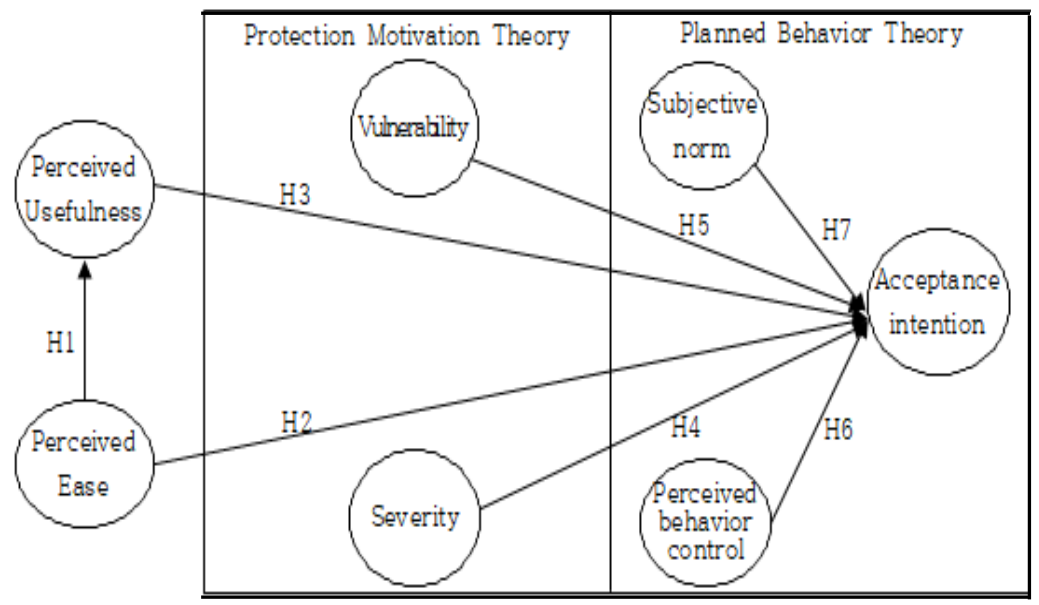

Figure 1. Research Model

From November 26 to 30, 2017, 98 questionnaires were collected from the metropolitan area. Operational definitions of questionnaires are shown in Table 2. 
Table 2. Operational Definition

\begin{tabular}{|c|c|c|c|}
\hline Domain & Metrics & Contents & Related Research \\
\hline \multirow{3}{*}{$\begin{array}{l}\text { Perceived } \\
\text { usefulness }\end{array}$} & 1 & $\begin{array}{l}\text { Running the Rewards app will help you get the rewards } \\
\text { you want }\end{array}$ & \multirow{3}{*}{$\begin{array}{l}\text { Nielson (2000), } \\
\text { Benbunnan-Fech (2001), } \\
\text { Parmer (2002), } \\
\text { Nicolae (2002), } \\
\text { Sohn Youngjoon, Kim } \\
\text { Hoktae (2011), Nielson } \\
\text { (2000) } \\
\text { Benbunnan-Fech (2001), } \\
\text { Parmer (2002), } \\
\text { Nicolae (2002), } \\
\text { Sohn Youngjoon, Kim } \\
\text { Hoktae (2011) }\end{array}$} \\
\hline & 2 & $\begin{array}{l}\text { The Rewards app helps you get your interests } \\
\text { (information) }\end{array}$ & \\
\hline & 3 & Helps you spend a lot of time using the Rewards app & \\
\hline \multirow{3}{*}{$\begin{array}{l}\text { Perceived } \\
\text { ease }\end{array}$} & 4 & $\begin{array}{l}\text { It's easy to learn how to use the Rewards app and is easy } \\
\text { to implement }\end{array}$ & \multirow{3}{*}{$\begin{array}{l}\text { Davis (1989), } \\
\text { Venkatesh \& Davis (2000), } \\
\text { Venkatesh (2006), } \\
\text { Sung Dongkyu (2009) } \\
\text { Park Jinpyu, Kim Jaeyoung } \\
\text { (2010), } \\
\text { Park isul, Woo Hyungjin } \\
(2013)\end{array}$} \\
\hline & 5 & The Rewards app is curious & \\
\hline & 6 & I am willing to continue to use the Rewards app. & \\
\hline \multirow{5}{*}{ Severity } & 7 & $\begin{array}{l}\text { When security is threatened when personal information is } \\
\text { provided to a reward app (personal information is leaked) } \\
\text { it will harm personal life (academic, work) }\end{array}$ & \multirow{5}{*}{$\begin{array}{l}\text { Rogers (1975), } \\
\text { Park Sisul, Woo Hyungjin } \\
\text { (2013), } \\
\text { Park Hyun-sun, Kim Sang- } \\
\text { hyun (2013), } \\
\text { Kim Min Sung, Kim Tae } \\
\text { Sung (2014), } \\
\text { Park Chan Wook, Lee } \\
\text { Sangwoo (2014) }\end{array}$} \\
\hline & 8 & $\begin{array}{l}\text { When providing personal information to the Rewards app, } \\
\text { the security issue (the problem of leakage of personal } \\
\text { information) may cause confusion in our society }\end{array}$ & \\
\hline & 9 & $\begin{array}{l}\text { Personal information security problems (privacy issues) } \\
\text { can cause confusion in the global network }\end{array}$ & \\
\hline & 10 & Running the Rewards app will consume a lot of baddies & \\
\hline & 11 & $\begin{array}{l}\text { Running the Rewards app will slow down your } \\
\text { smartphone reaction }\end{array}$ & \\
\hline \multirow{4}{*}{ Vulnerability } & 12 & $\begin{array}{l}\text { Vulnerability is likely to cause personal information data } \\
\text { loss (leak) when I use the Rewards app }\end{array}$ & \multirow{4}{*}{$\begin{array}{l}\text { Kim Minsung, Kim } \\
\text { Sungtae(2014), } \\
\text { Bowen(2005), } \\
\text { Althaus(2001, 2002) } \\
\text { Jung Ikjae(1996) }\end{array}$} \\
\hline & 13 & $\begin{array}{l}\text { I think someone is likely to collect uploaded personal } \\
\text { information to use the Rewards app without my consent }\end{array}$ & \\
\hline & 14 & Generally, I think the security of the Rewards app is weak & \\
\hline & 15 & $\begin{array}{l}\text { I believe there is a possibility of routine maintenance to } \\
\text { meet regulatory, policy and business needs }\end{array}$ & \\
\hline \multirow{3}{*}{$\begin{array}{l}\text { Subjective } \\
\text { norm }\end{array}$} & 16 & $\begin{array}{l}\text { Most people who matter to me will want to run the } \\
\text { Rewards app }\end{array}$ & \multirow{3}{*}{$\begin{array}{l}\text { Wang \& McChung (2011), } \\
\text { However, Current (2013), } \\
\text { Ju Jihyeok (2013) }\end{array}$} \\
\hline & 17 & $\begin{array}{l}\text { Most people who matter to me will say I like to run the } \\
\text { Rewards app }\end{array}$ & \\
\hline & 18 & $\begin{array}{l}\text { Most people who matter to me will recommend that I run } \\
\text { the Rewards app }\end{array}$ & \\
\hline \multirow{3}{*}{$\begin{array}{l}\text { Perceived } \\
\text { behavior } \\
\text { control }\end{array}$} & 19 & I can decide to run the Rewards app on my own initiative & \multirow{3}{*}{ Wang \& McChung (2011) } \\
\hline & 20 & Running the Rewards app is easy if I want to. & \\
\hline & 21 & It's entirely up to me whether I run the Rewards app & \\
\hline \multirow[b]{2}{*}{$\begin{array}{l}\text { Acceptance } \\
\text { intention }\end{array}$} & 22 & $\begin{array}{l}\text { I will use the Rewards app provided through collecting } \\
\text { and processing personal information (including allowing } \\
\text { personal information for use) }\end{array}$ & \multirow{2}{*}{$\begin{array}{l}\text { Davis, et al. (1989) } \\
\text { Venkatesh, Morris, } \\
\text { Davis (2003), } \\
\text { However, Han Young ho, } \\
\text { Park Youngae (2013) }\end{array}$} \\
\hline & 23 & $\begin{array}{l}\text { We are willing to recommend the Rewards app, which is } \\
\text { provided through the collection and processing of } \\
\text { personal information, to others (including allowing } \\
\text { personal information for use) }\end{array}$ & \\
\hline
\end{tabular}


The derived hypothesis is as follows.

Hypothesis 1. Ease will have a positive effect on usability.

Hypothesis 2. The financial help of a reward app will have a positive effect on the acceptance intention.

Hypothesis 3. The ease of using the Rewards app will have a positive effect on the acceptance intention.

Hypothesis 4. If personal information is leaked when providing personal information, security will be threatened and it will harm personal life (school, work) and will have a negative effect on acceptance intention.

Hypothesis 5. Reward apps are vulnerable, smartphone slowing and fast battery consumption will have a negative impact on acceptance.

Hypothesis 6. Subjective norms that feel good and beneficial for a reward app will have a positive effect on the acceptance intention.

Hypothesis 7. Perceived behavioral controls that determine the use of reward apps will have a positive effect on acceptance intentions.

The intention of acceptance was measured by the 23 item 5 - point scale, and the existing research models were used as a variable for the integrated model of protection motivation theory and planning action theory. Intention to accept is analyzed by age. The exploratory factor analysis was performed with SPSS 22, and confirmatory factor analysis of the fit, validity, reliability, and hypothesis test of the research model was performed with PLS (Partial Least Squares) 2.0.

\section{Results}

Feasibility refers to how accurately the measurement tools measure the constituent concept to be measured, and there are three types of content validity, criterion-related validity, and conceptual validity. The validity test is mainly used for factor analysis. The factor analysis is to know how accurately the concept to be measured is measured, and to check whether the variables to be measured are tied to the same factor. In this study, exploratory factor analysis was adopted to verify the validity. Factor analysis was used to examine the correlation between covariance and correlation in order to grasp the factors that are common among the variables. It is a technique to reduce the number of variables by identifying variables that can be well represented. In other words, it finds out the factors of high correlation and ties them together with homogeneous factors based on their commonality. By this, it is possible to reduce the uncertainty of data interpretation that may occur due to excessive information, it makes it easy. For the validity analysis of Table 3., SPSS 22 was used. The data were analyzed by taking into consideration the items with a commonality of 0.5 or more, the eigenvalues of 1.0 or more, and the criteria of 0.95 or more for each factor. In order to check the reliability of the items used in this study, the Cronbach- $\alpha$ coefficients of Table 4 . were confirmed through exploratory factor analysis. 
Table 3. Feasibility Validation

\begin{tabular}{|c|c|c|c|c|c|c|c|}
\hline \multirow{2}{*}{$\begin{array}{l}\text { Configuration } \\
\text { Concept }\end{array}$} & \multicolumn{7}{|c|}{ Factor } \\
\hline & Acceptance & Severity & Ease & Usefulness & Behavior & Subjective norm & Vulnerability \\
\hline Acceptance 1 & 0.914 & & & & & & \\
\hline Acceptance 2 & 0.926 & & & & & & \\
\hline Severity 1 & & 0.947 & & & & & \\
\hline Severity 2 & & 0.927 & & & & & \\
\hline Ease 1 & & & 0.644 & & & & \\
\hline Ease 2 & & & 0.794 & & & & \\
\hline Ease 3 & & & 0.923 & & & & \\
\hline Usefulness 1 & & & & 0.766 & & & \\
\hline Usefulness 2 & & & & 0.797 & & & \\
\hline Usefulness 3 & & & & 0.874 & & & \\
\hline Behavior 1 & & & & & 0.993 & & \\
\hline Behavior 2 & & & & & 0.758 & & \\
\hline Subjective Norm 1 & & & & & & 0.906 & \\
\hline Subjective Norm 2 & & & & & & 0.879 & \\
\hline Subjective Norm 3 & & & & & & 0.834 & \\
\hline Vulnerability 1 & & & & & & & 0.762 \\
\hline Vulnerability 2 & & & & & & & 0.782 \\
\hline Vulnerability 3 & & & & & & & 0.811 \\
\hline
\end{tabular}

Table 4. Cronbach's $\alpha$

\begin{tabular}{cccccccc}
\hline Factor & Acceptance & Severity & Ease & Usefulness & Behavior & Subjective norm & Vulnerability \\
\hline Cronbach's $\alpha$ & 0.819 & 0.862 & 0.710 & 0.745 & 0.808 & 0.846 & 0.725 \\
\hline
\end{tabular}

The reliability of all items was obtained with a Kronbach alpha coefficient of 0.7 or higher. Confirmatory factor analysis (CFA) is a factor analysis based on the theoretical background, in order to verify the validity of a measurement model. It is a means to confirm the hypothesis. To validate the variables used for the research model, the conceptual validity, the central validity, and the validity of the discrimination were tested. The validity of the concept was confirmed by confirming whether the observational variables constituting the variables were constructed with proper concepts and definitions and intensive validity means that the latent variable explanatory power of the observational variables constituting the variable is valid. Discriminatory validity is a validation test to determine whether there is no duplication or similarity between concepts composed of two or more latent variables and whether there is a difference. The conceptual validity is validated when the standardized coefficient value is 0.5 or more, the intrinsic validity is 0.6 or more, the variance extraction index is 0.5 or more, and the discriminant validity is the validity if the value of the variance extraction index (representing the information amount of variance). Table 5. Verification Result of model reliability of confirmatory factor analysis.

The correlation coefficient between the latent variable and the AVE square root of the latent variable is analyzed and it is judged validity when the AVE value of the specific latent variable is larger than the correlation coefficient between latent variable and other latent variable. The results of this study are as follows. First, the correlation between the AVE value and the latent variable was higher than the correlation coefficient between the latent variable and the other latent variables. Hypothesis tests showed that the p-values of $\mathrm{H} 1, \mathrm{H} 2$, and $\mathrm{H} 7$ were over 0.05 , and the remaining hypotheses, $\mathrm{H} 3, \mathrm{H} 4, \mathrm{H} 5$, and $\mathrm{H} 6$, were rejected. 
Table 5. Hypothesis Verification Result

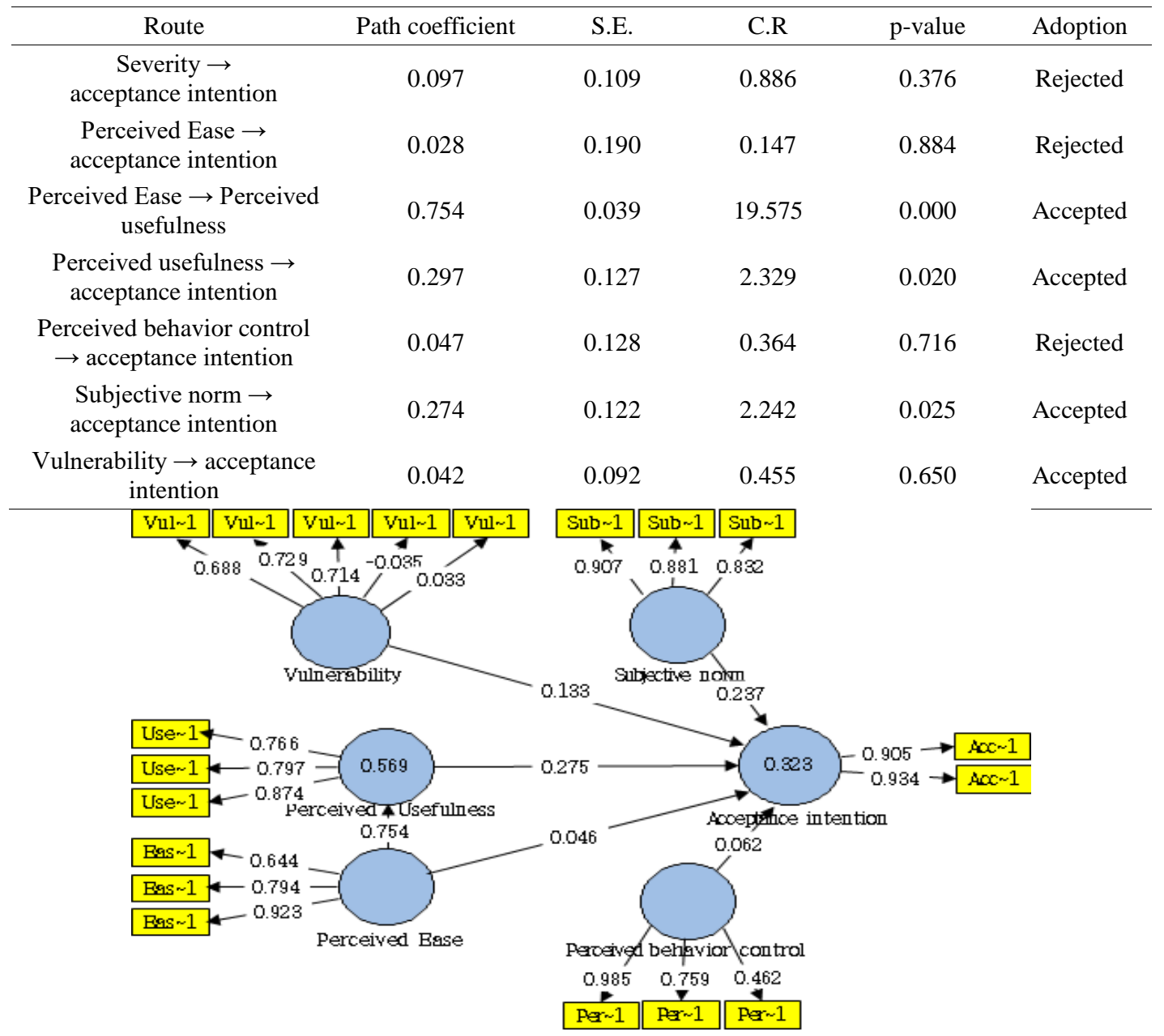

\section{Conclusion}

As a result, I installed the reward app with my intention, so I can continue to accept it even if there are concerns about ease of use or security vulnerability. If the speed of the smartphone is low or there is not a problem of battery charging, the intention to use is generally high because there are many advantages in terms of usability. It is necessary to maintain a good strategic reputation and to complement strategies by comparing the services of various existing competitors. After analyzing the general environment of the society, analyzing the environment in the industry, analyzing the value chain, analyzing the competencies of $7 \mathrm{~S}$ and $\mathrm{BSC}$, and establishing the corporate vision and strategy through analyzing the portfolio, SWOT, Blue Ocean Strategy and overall IT trend, You will be able to advance your success. In addition, we recommend using Big Data for inspirational and rapid decision making. Based on a deep understanding of customers, we make use of various benefits such as user ID, reward app, GPS information, carrier, OS, device type, etc., by utilizing the advantage of programmer's advertisement such as campaigns setting and target setting. It should be worried about whether or not it will provide optimal contrast.

\section{References}

[1] S. Y. Yu and J. H. Kim, "The Effect of Reward Application Motivation, Benefit and Loss Factors on Recommendation Intention”, Korean Psychological Association, (2014), pp. 279-306. 
[2] M. K. Han, Y. Yang and Y. H. Sung, "A Study on the Influence of Smartphone Reward Application Type on Recommendation Intention", Korea Brand Design Society, (2015), pp. 1-3.

[3] H. Lee, "Sports Toto's gambling debate", Korean Journal of Physical Education, (2010), pp. 6-7.

[4] J. Ki Lee, "An Exploratory Study on the Effect of Reward Application Advertising", Social Science Research Review, (2016), pp. 4-8.

[5] S. Yeob Yu and J. Hee Kim, "The Effect of Reward Application Motivation, Benefit and Loss Factors on Recommendation Intention”, Korean Journal of Consumer and Advertising Psychology, (2014), pp. 4-8.

[6] J. Sung Jung, E. Chang Choi and S. Hoon Kwak, "Implementation of check-in service and management function in location-based check-in reward system", Korea Institute of Communication Sciences, (2013), pp. $1-2$.

[7] S. A Choi, HwangWoo Noh, "A Study on Usability Evaluation of Reward App", The Korea Contents Society, (2016), pp. 1-2.

[8] S. Jung Kim, G. Hyung Lee and M. Kum Han, "The effect of the type of point exhaustion on user's preference, satisfaction and intention of mobile reward app", The Korea Contents Society, (2014), pp. 34.

[9] R. M. Bowen, A. K. Davis and D. A. Matsumoto, "Emphasis on Pro Forma versus GAAP Earnings in Quarterly Press Release: Determinants, SEC Intervention, and Market Reactions", The Accounting Review, vol. 80, no. 4, (2005), pp. 1011-1038.

[10] D. Sup Youm, "A Study on Factors Affecting Satisfaction of Smartphone Rewards Application Focused on Usage Motivation, Perceived Attributes", Brand Design Association of Korea, (2014), pp. 34.

[11] W. Chun Oh, T. Ho Kang and N. Yoon Kwak, "Watch content surveillance system for mobile reward ad app", Proceedings of Symposium of the Korean Institute of communications and Information Sciences, (2015), pp. 1-2.

[12] J. Ki Lee, "An Exploratory Study on the Effects of Reward Application Advertising - Focusing on the Acceptance Intention, Recommendation Intention, and Purchase Intention of Rewards App of College Students, Social Science Research Review, (2016), pp. 3-7.

[13] H. Lee and S. Jung, "Symbol analysis of mobile reward app GUI content for usability improvement", Korea Society of Basic Design \& Art, (2013), pp. 3-4.

[14] Multivariate data analysis (5th ed.). Upper Saddle River, NJ: Prentice Hall., Hair, J.F., Anderson, R.E., Tatham, R. L., \& Black, W. C., (1998).

[15] Psychometric theory (2nd ed.). New York, NY: McGraw-Hill. Nunnally, J.L., (1978).

[16] Education measurement (2nd ed., 443-507). Washington, D.C.: American Council on Education., Cronbach, L.J.. Test validation. In R.L. Thorndike (eds.), (1971).

[17] M. Sung Kim and S. Tae Kim, "A Study on the Effect of Personal Information Exposure on the Intention of the Right to Be Forgotten", Korean Media Scholarship, (2014), pp. 35-36.

[18] I. Jae Chung, "A Study on the Implementation Plan of Information Protection Policy in the United States", Information Security Review, vol. 1, no. 1, pp. 40-60, (1996).

\section{Authors}

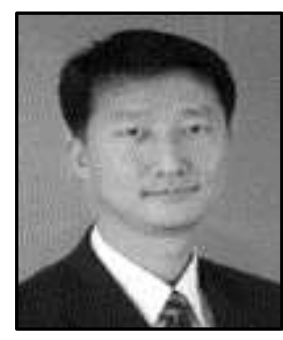

\section{Dong-Jin Choi}

Feb. 1991 : B.S Computer Science, Dongguk University

Feb. 2008 : M.S. Information System, Yonsei University

Dec. 2017 : Ph.D Completion IT Policy and Management, Soongsil

University

2000 Present Working at LG U +

<Interesting> IT Strategy, Information Security, IT Governance

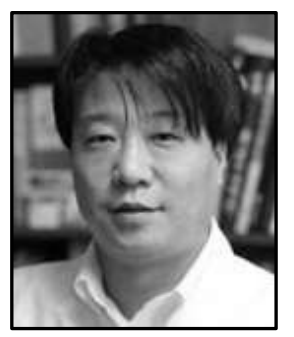

Yongtae Shin

Feb. 1985 : B.S Department of Industrial Engineering, Hanyang

University

Dec. 1990 : M.S Univ. of Iowa, Computer Science

May 1994 : Ph.d Univ. of Iowa, Computer Science

Mar. 1995 Present : Prof. in School of Computer Science and

Engineering, Soongsil Univ.

<Interesting> Content Security, IoT, Information Security, Next

Generation Internet 